Contract No. and Disclaimer:

This manuscript has been authored by Savannah River Nuclear Solutions, LLC under Contract No. DE-AC09-08SR22470 with the U.S. Department of Energy. The United States Government retains and the publisher, by accepting this article for publication, acknowledges that the United States Government retains a non-exclusive, paid-up, irrevocable, worldwide license to publish or reproduce the published form of this work, or allow others to do so, for United States Government purposes. 


\title{
Atmospheric Effects on the Performance of CdZnTe Single-Crystal Detectors
}

\author{
AARON L. WASHINGTON II, ${ }^{1,4}$ LUCILE C. TEAGUE, ${ }^{2}$ \\ MARTINE C. DUFF, ${ }^{1}$ ARNOLD BURGER,${ }^{3}$ MICHAEL GROZA,${ }^{3}$ \\ and VLADIMIR BULIGA ${ }^{3}$ \\ 1.-Savannah River National Laboratory, 773-42A, Aiken, SC 29808, USA. 2.-999-2W, Aiken, \\ SC 29808, USA. 3.-Fisk University, Nashville, TN 37208-3051, USA. 4.-e-mail: aaron. \\ washington@srnl.doe.gov
}

The production of high-quality ternary single-crystal materials for radiation detectors has progressed over the past 15 years. One of the more common materials being studied is CdZnTe (CZT), which can be grown using several methods to produce detector-grade materials. The work presented herein examines the effects of environmental conditions including temperature and humidity on detector performance [full-width at half-maximum (FWHM)] using the single pixel with guard detector configuration. The effects of electrical probe placement, reproducibility, and aging are also presented.

Key words: CZT, temperature, humidity, detector performance, electrical probe placement reproducibility

\section{INTRODUCTION}

Research into the development of room-temperature efficient $\mathrm{x}$-ray and gamma-ray detectors originally emphasized the use of classical primary materials such as silicon and germanium. ${ }^{1}$ In recent years, research has focused more towards using higher-Z devices such as CdZnTe (CZT) and CdTe due to their high cross-section for photoelectric absorption, small electronics package, and roomtemperature operation (no cryogenic cooling requirement). Under specific growth conditions, high-quality CZT crystals can be produced for use as room-temperature gamma- and $\mathrm{x}$-ray detectors. Traditional methods for producing these materials include, but are not limited to: modified vertical Bridgman methods (MVB), the traveling heater method (THM), and temperature gradient solution growth (TGSG). Compared with traditional semiconductor radiation detectors such as silicon and germanium, ternary compound semiconductors such as CZT are advantageous due to their wide range of physical properties and potential for roomtemperature operation. ${ }^{2}$

(Received September 18, 2009; accepted March 10, 2010)
The use of CZT material as a gamma radiation spectrometer is an optimal choice due to its wide bandgap and high atomic number. Recent progress has been made to improve material development and, in some cases, has refined the research focus for making and studying these types of materials.,4 For example, problems with defects such as pipes have been resolved; however, defects which occupy smaller crystal volumes such as secondary phases (SP) are presently one of the major concerns with regard to gamma spectrometer performance, as discussed and reviewed by Duff et al. ${ }^{5}$

The environmental operating conditions for CZT detectors have mostly been overlooked in terms of understanding overall detector performance. Roomtemperature detection of gamma and x-ray radiation encompasses a range of atmospheric conditions, so there is a need to understand performance under such conditions. In addition to investigating performance under various atmospheric conditions, it should be established that performance-based measurements (when evaluating materials such as CZT for radiation spectrometers) need to be highly reproducible with respect to time and electrical probe placement. The overall distribution verifies that a good baseline measurement has been established for the material. It has been shown that 
atmospheric conditions have some effect on detector performance, mainly based on the significant linewidth broadening of photoluminescence spectra with increasing temperature. ${ }^{6,7}$ There have also been studies that have investigated the influence of temperature on electron mobility within the crystal. ${ }^{8}$ In addition, there is some experimental information in the literature that supports the theory that temperature significantly affects CZT detector performance. ${ }^{2,9}$ According to Greaves et al., ${ }^{10}$ there is significant degradation in detector performance on both sides of $0^{\circ} \mathrm{C}$, where the pulser remains mostly unaffected by temperature. However, the data presented by these researchers do not show a decrease in detector performance with increasing temperature, whereas when the temperature is lowered, there is a decrease in detector performance. In addition, no results have been reported on the effects of relative humidity on spectrometer performance of CZT single-crystal detectors.

In the work presented herein, we investigated the effects of humidity and temperature on the performance of the detector using a highly controlled atmospheric chamber with an ${ }^{241} \mathrm{Am}$ source to generate gamma emission at $59.6 \mathrm{keV}$. We also report herein the reproducibility of detector measurements with both stationary and reapplied electrical probes.

\section{EXPERIMENTAL PROCEDURES}

The CZT sample used in this study was grown using THM with incorporation of $10 \% \mathrm{Zn}$, as shown previously, ${ }^{11,12}$ and was provided by Redlen Technologies (Victoria, BC, Canada). The CZT crystal measured $10 \mathrm{~mm} \times 10 \mathrm{~mm} \times 2.1 \mathrm{~mm}$ and is referred to as "Redlen 64039A." The sample was polished with standard techniques down to a clean smooth surface with $0.05-\mu \mathrm{m}$ alumina. Gold contacts were sputtered onto the crystal in a singlepixel geometry with a guard electrode ${ }^{13}$ to allow for detector performance testing using a ${ }^{241} \mathrm{Am}$ (59.6 keV) gamma source (Fig. 1). The pixel was $7 \mathrm{~mm}$ in diameter with a gap of $250 \mu \mathrm{m}$.

The resolution of the peak was calculated by dividing the FWHM of the energy peak by the energy

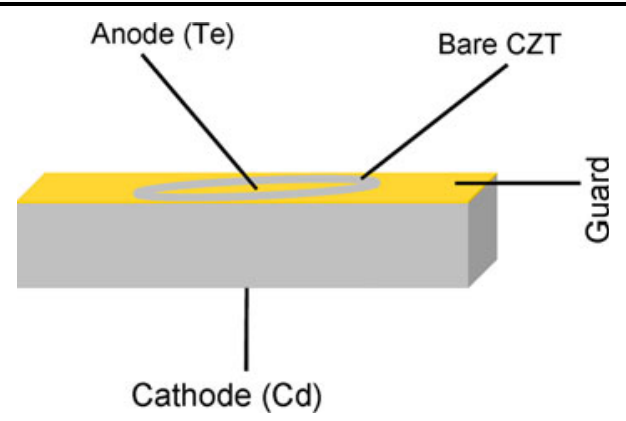

Fig. 1. A schematic of the single pixel with grounded guard detector design, illustrating the configuration used for these studies. The pixel is $7 \mathrm{~mm}$ in diameter with a gap of $250 \mu \mathrm{m}$. of the gamma source $\left(59.6 \mathrm{KeV}^{241} \mathrm{Am}\right)$. Similarly, the distribution was determined by calculating the standard deviation for the measurements taken and dividing by the average. To obtain the optical performance data for the detector, an Amtek A250 CF charge-sensitive preamplifier (Oak Ridge, TN) was used in addition to an Ortek (Oak Ridge, TN) amplifier. These instruments were coupled to a multichannel analyzer (Cambera, Meriden, CT).

Atmospheric measurements were performed using a modified performance box, where the internal temperature and humidity were controlled externally. The temperature was altered using a microheating system that allowed the temperature to be controlled from $0^{\circ} \mathrm{C}$ up to $50^{\circ} \mathrm{C}$. During the controlled-temperature experiment, humidity was maintained at $0 \%$ by passing dry air through the chamber to remove moisture from the air. To vary the humidity, the sample was placed inside a sealed atmospheric chamber, where the temperature and humidity could be controlled and monitored. Humidity was increased by placing water inside the chamber and allowing it to evaporate. During atmospheric measurements, no surface passivation or protective encapsulation measures were taken to protect the surface in any manner.

\section{RESULTS AND DISCUSSION}

\section{Atmospheric Effects}

The effects of relative humidity on detector performance were measured to determine whether optimal relative humidity was required to increase detector performance. However, we observed very little change in performance with respect to atmospheric water content. The Redlen crystals were measured without any protective coating or surface passivation in order to determine the actual effect of water vapor on the performance of the bare, exposed crystal surface. Figure 2 shows the changes in detector performance as the relative humidity of the sample chamber was varied from $29 \%$ to $86 \%$. The temperature was maintained at $21.2^{\circ} \mathrm{C}$ throughout the entire experiment. The average FWHM observed for this humidity range was $3.60 \pm 0.14 \mathrm{keV}$ with average pulser width of $2.51 \pm 0.10 \mathrm{keV}$. The average energy resolution of the detector over the entire humidity range was calculated to be $6.04 \%$. Although the distribution of the measured values was relatively high at $3.9 \%$, this value remained within the experimental error of the measurement.

In addition to investigating the effects of humidity, we have also examined the performance of the material in various temporal environments. The temperature was varied from $-5^{\circ} \mathrm{C}$ up to $50^{\circ} \mathrm{C}$ at a constant relative humidity of nearly $0 \%$ to ascertain the changes in material performance at these temperatures. In Fig. 3a, the full-width at half-maximum (FWHM) of the peak is plotted as a function of temperature while the bias was maintained at either $200 \mathrm{~V}$ or $300 \mathrm{~V}$. The average error in each 


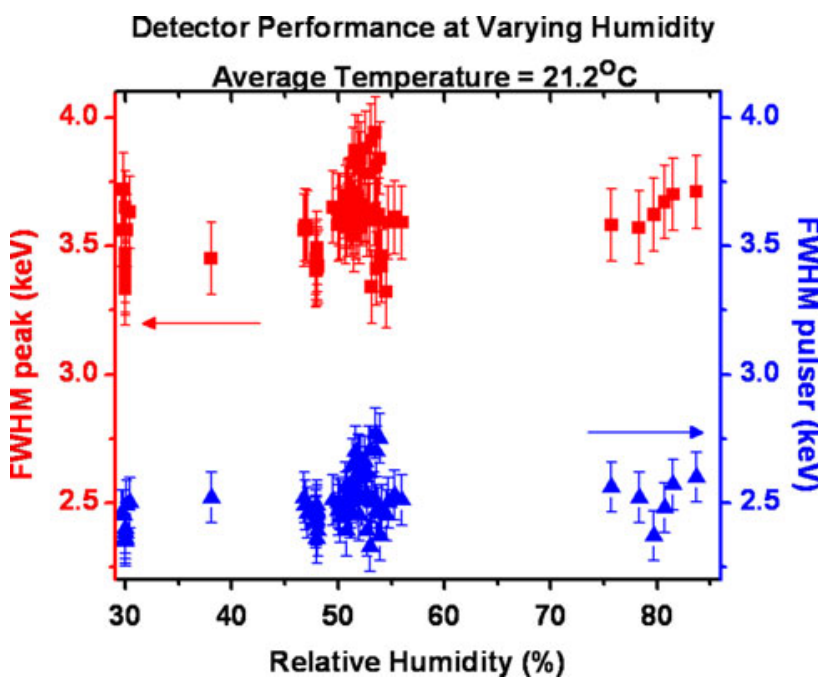

Fig. 2. Plot of the FWHM of the detector peak (squares, left $Y$-axis) and electronic pulser (triangles, right $Y$-axis) as a function of relative humidity (\%). The cathode was kept constant during the humidity study, and the average temperature was $21.2^{\circ} \mathrm{C}$.

measurement was determined to be $1.54 \%$, indicating that the measurements were conducted precisely. The average error was calculated by dividing the error by the total number of replications at each statistical point. In Fig. 3b, the peak resolution relative to the gamma radiation energy is plotted versus temperature at both $200 \mathrm{~V}$ and $300 \mathrm{~V}$. The differences observed at the different applied voltage biases indicate that there was an increase in carrier density with increasing bias (electric field) that resulted in better radiation spectrometer performance. Figure 3 shows that CZT detector performance was greatly affected by temperature, with performance decreasing with increasing temperature. When changing temperature in conjunction with the bias, one expects an increase in detector performance at higher bias as well as a greater decrease in performance as temperature increases, as was observed in the data.

In terms of resolution, the distribution in the plotted value was calculated to be $1.54 \%$. The temperature plots show that there was a significant increase in peak width (indicating a decrease in detector performance) as the temperature increased above $25^{\circ} \mathrm{C}$. The peak width continued to increase at an exponential rate as the temperature continued to increase. However, the performance of the detector increased slightly on lowering the temperature below room temperature, consistent with literature reports. ${ }^{4}$ Based on our data, we conclude that an increase in temperature adversely affects detector performance to well below an acceptable level, and our results demonstrate that CZT detector materials must be kept at $25^{\circ} \mathrm{C}$ or cooler to achieve optimum performance.

\section{Reproducibility Studies}

The reproducibility of our detector performance measurements was investigated based on the
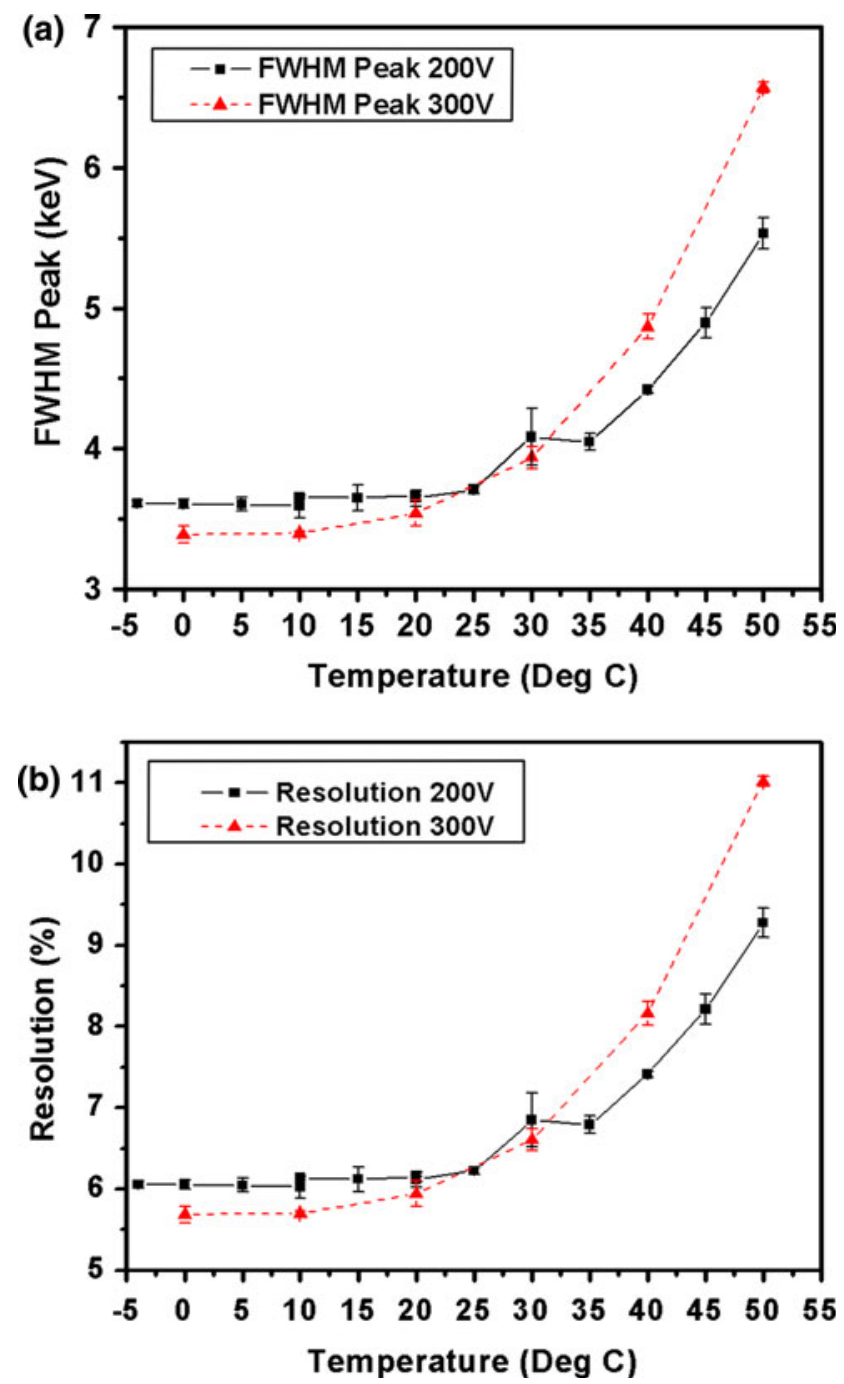

Fig. 3. Detector performance for measuring ${ }^{241} \mathrm{Am}$ gamma radiation as a function of temperature: (a) FWHM peak and (b) resolution (\%), as determined based on the energy of the gamma radiation source. Humidity was maintained at nearly $0 \%$.

FWHM of the ${ }^{241} \mathrm{Am}$ peak at $20^{\circ} \mathrm{C}$ and $48 \%$ humidity, as shown in Fig. 4a. The guarded singlepixel configuration produced an average FWHM at these conditions of $3.44 \pm 0.03 \mathrm{keV}$ with the pulser measuring at $2.44 \pm 0.04 \mathrm{keV}$. A spectrum of the best performance data point is shown in Fig. $4 \mathrm{~b}$, with the peak at $59.6 \mathrm{keV}$ and the pulser shown at $83 \mathrm{keV}$. Relative to the energy of the gamma emission, this peak width produces an energy resolution of $5.77 \%$, making this a high-performance detector. For the graphs shown herein, the actual starting time was set at the initial completion of the CZT polish and Au contact deposition. The setup and instrument calibration time between sample preparation and the first detector measurement was approximately $2 \mathrm{~h}$.

After 3 months of ambient storage with no special control of the local atmosphere, the sample was 

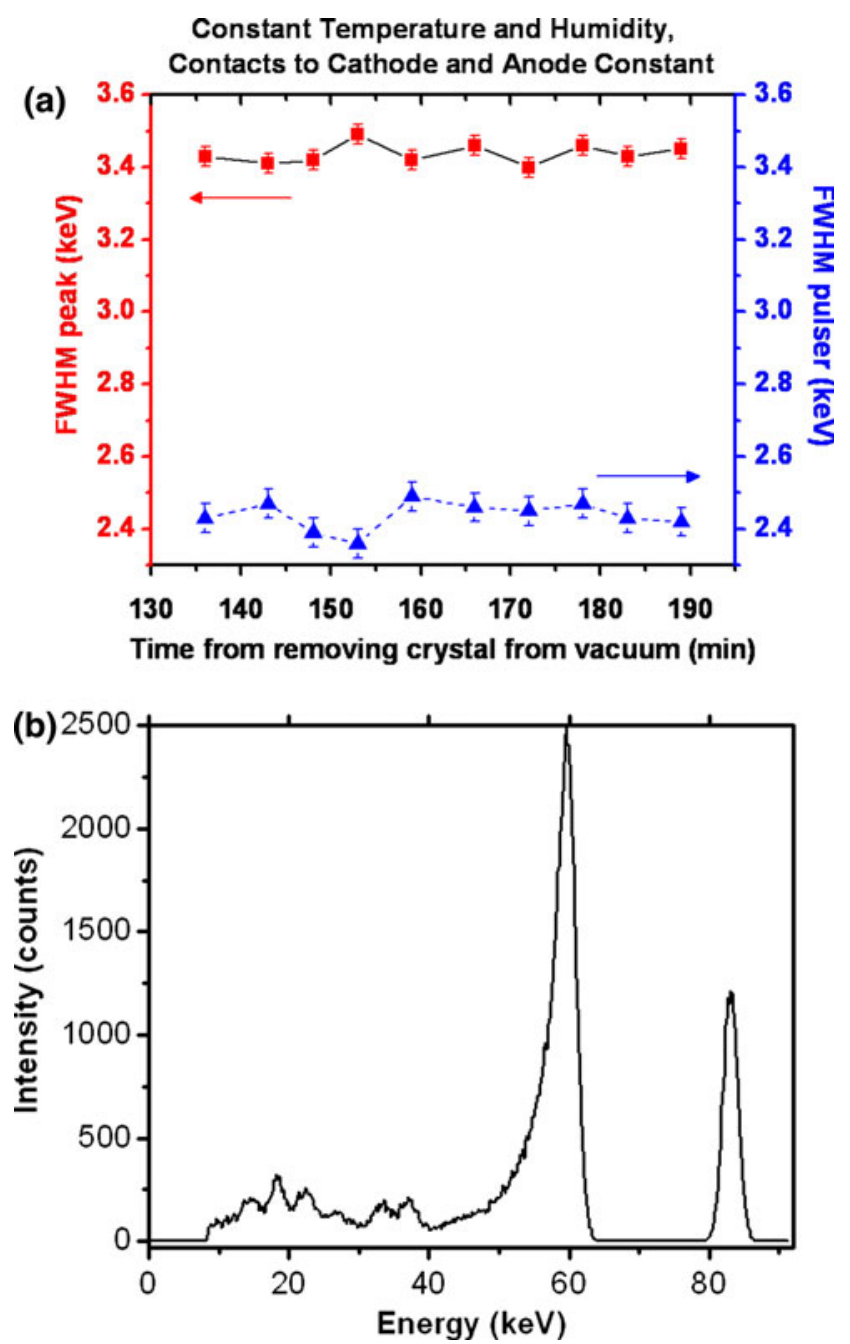

Fig. 4. (a) Detector performance measurement of as-polished CZT material $2 \mathrm{~h}$ after preparation, as determined by the FWHM of the peak (squares, left $Y$-axis) and pulser (triangles, right $Y$-axis). Zero time indicates when the crystal was taken out of vacuum after polishing and photolithography. (b) The spectrum (including pulser) from the best data point versus energy, normalized to $59.6 \mathrm{keV}$ at the peak.

retested to determine the effect of aging on the gamma radiation detector performance at $24.6^{\circ} \mathrm{C}$ and $55 \%$ relative humidity (Fig. 5). These conditions differed only slightly from those of the initial measurements $\left(20^{\circ} \mathrm{C}\right.$ and $48 \%$ relative humidity).

Following storage, the peak width of the detector was measured to be $3.59 \pm 0.04 \mathrm{keV}$, indicating a slight decrease in performance in the material over the aging timeframe, with a detector resolution of $6.02 \%$. In addition, the pulser peak width had also increased to $2.51 \pm 0.04 \mathrm{keV}$. A spectrum from the best performance data point is shown in Fig. $5 \mathrm{~b}$ with the peak at $59.6 \mathrm{keV}$ and the pulser at about $83 \mathrm{keV}$. We attribute this decrease in performance to the slight increase in temperature at the time of the measurement compared with our initial measurements, as described in the previous section.
Detector Performance after Three Months Ambient Storage Conditions: Average $\mathrm{T}=\mathbf{2 4 . 6}{ }^{\circ} \mathrm{C}$, Average Rel. Hum. $=\mathbf{5 5 . 5} \%$
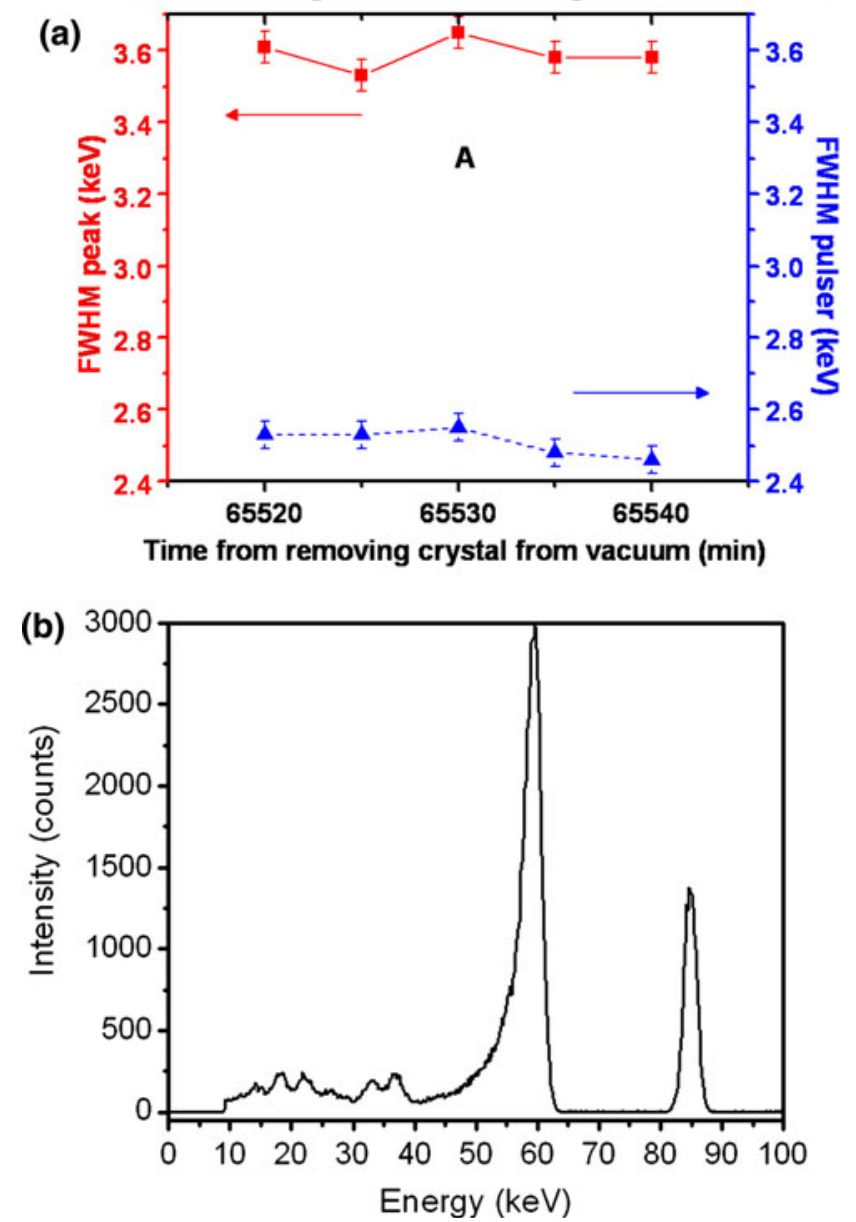

Fig. 5. (a) Long-term stability of CZT stored in ambient conditions, as measured by the change in the FWHM, indicated by squares for the sample (left $Y$-axis) and by triangles for the pulser (right $Y$-axis). Zero time indicates when the crystal was taken out of vacuum after polishing and photolithography. (b) Spectrum (including pulser) from the best data point plotted versus energy, normalized to $59.6 \mathrm{keV}$ at the peak.

\section{Electrical Probe Placement Reproducibility}

Previous literature reports indicate that both the quality of the surface and the quality of the contact between the external electrical probes and the $\mathrm{Au}$ on the crystal surface ${ }^{14,15}$ greatly affect the performance of the crystal. To avoid discrepancies caused by the placement of external electrical probes, the reproducibility of probe placement on the surface was determined by removing and reapplying the external electrical probe at the anode contact. The results are shown in Fig. 6. The temperature and humidity were held constant during these measurements at $21.2^{\circ} \mathrm{C}$ and $52.8 \%$, respectively. The electrical probes were replaced a total of three times, with five detector measurements performed between each replacement. In section A of Fig. 6, the average peak width was determined to be $3.39 \pm 0.06 \mathrm{keV}$ with a pulser width of 


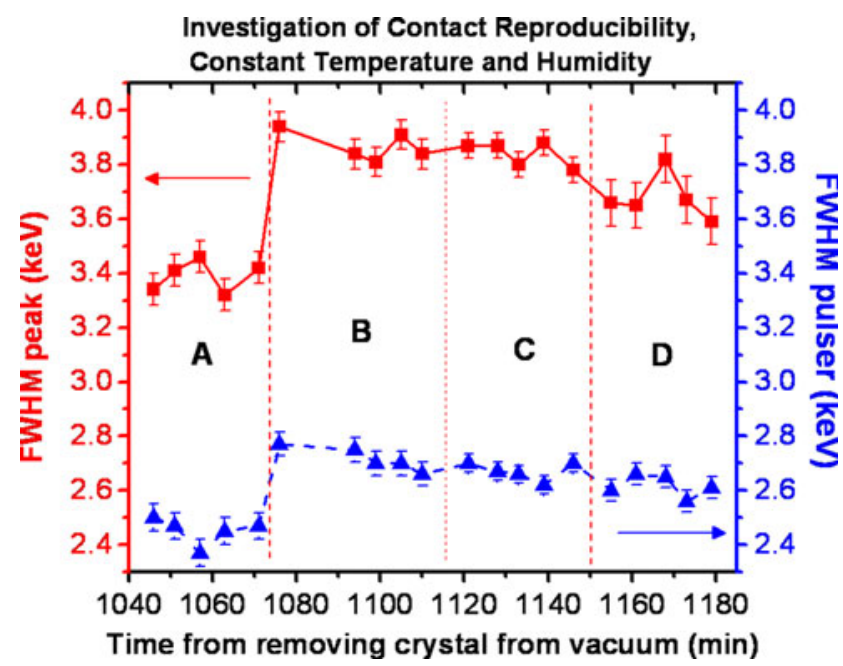

Fig. 6. Reproducibility of electrical probe placement on CZT material as a function of the FWHM of the peak (squares) and pulser (triangles). The vertical dashed lines indicate where the contact was removed and replaced. The different sections created by contact replacement are labeled $\mathrm{A}, \mathrm{B}, \mathrm{C}$, and $\mathrm{D}$.
$2.45 \pm 0.05 \mathrm{keV}$, which is equivalent to a resolution of $5.69 \%$. In section B of Fig. 6 , the average peak width was determined to be $3.87 \pm 0.05 \mathrm{keV}$ with a pulser width of $2.72 \pm 0.05 \mathrm{keV}$, which is equivalent to a resolution of $6.49 \%$. In section $\mathrm{C}$ of Fig. 6 , the average peak width was determined to be $3.84 \pm$ $0.05 \mathrm{keV}$ with a pulser width of $2.67 \pm 0.03 \mathrm{keV}$, which is equivalent to a resolution of $6.44 \%$. In section D of Fig. 6, the average peak width was determined to be $3.68 \pm 0.08 \mathrm{keV}$ with a pulser width of $2.62 \pm 0.04 \mathrm{keV}$, which is equivalent to a resolution of $6.17 \%$. The increase in the FWHM of the peak and pulser observed between sections A and $B$ was caused by slight physical damage (scratching) to the surface of the crystal during probe replacement. Surface damage caused by improper placement of the external probe on the surface caused a similar effect as seen previously, resulting in an increase in resolution of the crystal. ${ }^{7}$ Overall, the peak and pulser FWHM showed less than a $2 \%$ distribution for each section, indicating

Table I. Data from Figs. 2-6, allowing direct comparison of each value based on the various analysis parameters

\begin{tabular}{|c|c|c|c|c|c|c|}
\hline Variable Tested & $\begin{array}{l}\text { Applied } \\
\text { Bias (V) }\end{array}$ & Replication & $\begin{array}{c}\text { FWHM (keV) } \\
\text { Peak }\end{array}$ & Error $( \pm)$ & $\begin{array}{c}\text { FWHM (keV) } \\
\text { Pulser }\end{array}$ & Error $( \pm)$ \\
\hline Short-term reproducibility & 300 & 10 & 3.437 & 0.028 & 2.437 & 0.040 \\
\hline Aging stability & 300 & 5 & 3.590 & 0.044 & 2.510 & 0.038 \\
\hline $\begin{array}{l}\text { Humidity }(30 \%) \\
\text { Humidity }(48 \%) \\
\text { Humidity }(50-55 \%) \\
\text { Humidity }(76-84 \%)\end{array}$ & $\begin{array}{l}300 \\
300 \\
300 \\
300\end{array}$ & $\begin{array}{r}10 \\
13 \\
50 \\
6\end{array}$ & $\begin{array}{l}3.509 \\
3.468 \\
3.650 \\
3.642\end{array}$ & $\begin{array}{l}0.134 \\
0.063 \\
0.135 \\
0.061\end{array}$ & $\begin{array}{l}2.414 \\
2.449 \\
2.538 \\
2.517\end{array}$ & $\begin{array}{l}0.054 \\
0.043 \\
0.101 \\
0.083\end{array}$ \\
\hline $\begin{array}{l}\text { Electrical probe placement reproducibility A } \\
\text { Electrical probe placement reproducibility B } \\
\text { Electrical probe placement reproducibility C } \\
\text { Electrical probe placement reproducibility D }\end{array}$ & $\begin{array}{l}300 \\
300 \\
300 \\
300\end{array}$ & $\begin{array}{l}5 \\
5 \\
5 \\
5\end{array}$ & $\begin{array}{l}3.390 \\
3.868 \\
3.840 \\
3.678\end{array}$ & $\begin{array}{l}0.058 \\
0.055 \\
0.046 \\
0.085\end{array}$ & $\begin{array}{l}2.452 \\
2.716 \\
2.670 \\
2.616\end{array}$ & $\begin{array}{l}0.049 \\
0.044 \\
0.033 \\
0.040\end{array}$ \\
\hline $\begin{array}{l}\text { Temperature }\left(0^{\circ} \mathrm{C}\right) \\
\text { Temperature }\left(10^{\circ} \mathrm{C}\right) \\
\text { Temperature }\left(20^{\circ} \mathrm{C}\right) \\
\text { Temperature }\left(30^{\circ} \mathrm{C}\right) \\
\text { Temperature }\left(40^{\circ} \mathrm{C}\right) \\
\text { Temperature }\left(50^{\circ} \mathrm{C}\right)\end{array}$ & $\begin{array}{l}300 \\
300 \\
300 \\
300 \\
300 \\
300\end{array}$ & $\begin{array}{l}3 \\
3 \\
3 \\
3 \\
3 \\
3\end{array}$ & $\begin{array}{l}3.389 \\
3.397 \\
3.541 \\
3.936 \\
4.868 \\
6.568\end{array}$ & $\begin{array}{l}0.060 \\
0.015 \\
0.093 \\
0.080 \\
0.087 \\
0.038\end{array}$ & $\begin{array}{l}2.232 \\
2.305 \\
2.439 \\
2.744 \\
3.531 \\
4.618\end{array}$ & $\begin{array}{l}0.636 \\
0.599 \\
0.607 \\
0.657 \\
0.738 \\
1.224\end{array}$ \\
\hline $\begin{array}{l}\text { Temperature }\left(-4^{\circ} \mathrm{C}\right) \\
\text { Temperature }\left(0^{\circ} \mathrm{C}\right) \\
\text { Temperature }\left(5^{\circ} \mathrm{C}\right) \\
\text { Temperature }\left(10^{\circ} \mathrm{C}\right) \\
\text { Temperature }\left(15^{\circ} \mathrm{C}\right) \\
\text { Temperature }\left(20^{\circ} \mathrm{C}\right) \\
\text { Temperature }\left(25^{\circ} \mathrm{C}\right) \\
\text { Temperature }\left(30^{\circ} \mathrm{C}\right) \\
\text { Temperature }\left(35^{\circ} \mathrm{C}\right) \\
\text { Temperature }\left(40^{\circ} \mathrm{C}\right) \\
\text { Temperature }\left(45^{\circ} \mathrm{C}\right) \\
\text { Temperature }\left(50^{\circ} \mathrm{C}\right)\end{array}$ & $\begin{array}{l}200 \\
200 \\
200 \\
200 \\
200 \\
200 \\
200 \\
200 \\
200 \\
200 \\
200 \\
200\end{array}$ & $\begin{array}{l}3 \\
3 \\
3 \\
5 \\
3 \\
8 \\
3 \\
3 \\
3 \\
3 \\
3 \\
3\end{array}$ & $\begin{array}{l}3.611 \\
3.609 \\
3.604 \\
3.361 \\
3.649 \\
3.652 \\
3.709 \\
4.084 \\
4.049 \\
4.419 \\
4.897 \\
5.530\end{array}$ & $\begin{array}{l}0.025 \\
0.031 \\
0.049 \\
0.080 \\
0.091 \\
0.032 \\
0.028 \\
0.201 \\
0.062 \\
0.024 \\
0.109 \\
0.111\end{array}$ & $\begin{array}{l}2.274 \\
2.210 \\
2.308 \\
2.285 \\
2.277 \\
2.344 \\
2.380 \\
2.687 \\
2.728 \\
3.259 \\
3.701 \\
4.515\end{array}$ & $\begin{array}{l}0.733 \\
0.767 \\
0.711 \\
0.044 \\
0.754 \\
0.047 \\
0.728 \\
0.778 \\
0.725 \\
0.657 \\
0.704 \\
0.683\end{array}$ \\
\hline
\end{tabular}

The sample is a Redlen crystal (64039A) with Au contacts in single-pixel geometry on the anode. 
very little variation in the measurements. The distribution between probe placement in the last three sections was $<3 \%$, and we conclude that replacing the electrical probes on the Au contacts multiple times does not have a significant effect on detector performance, unless the crystal is damaged during probe placement.

\section{CONCLUSIONS}

Herein, we have addressed CZT detector performance with respect to measurement reproducibility, long-term stability, and reproducibility of electrical probe placement in an effort to verify that detector performance is unaffected by these factors. The data from these measurements have been assembled into Table I for reference. To our knowledge, this is the first systematic study showing the changes in CZT detector performance as a function of changing atmospheric conditions, specifically humidity and temperature. Humidity had little effect on detector performance, whereas increasing temperature dramatically decreased the performance of the material. In contrast, a decrease in temperature below freezing had no statistically significant effect on the performance of the material over the temperature range investigated herein.

\section{ACKNOWLEDGEMENTS}

This work was supported by the US DOENational Nuclear Security Administration through the Office of Nonproliferation Research and Development-NA-22 and the National Science Foundation through the Fisk University Center for Physics and Chemistry of Materials (CPCoM), Cooperative Agreement CA: HRD-0420516 (CREST program) and through the US DOE NA-22, Grant No.
DE-FG52-05NA27035. We thank Redlen Technologies for supplying the crystal for our studies.

\section{REFERENCES}

1. T.E. Schlesinger, J.E. Toney, H. Yoon, E.Y. Lee, B.A Burnett, L. Franks, and R.B. James, Mater. Sci. Eng. R 32, 103 (2001).

2. G.F. Knoll, Radiation Detection and Measurement, 3rd ed. (New York, NY, USA: Wiley, 1999), p. 354.

3. A. Burger, M. Groza, Y. Cui, U.N. Roy, D. Hillman, M. Guo, L. Li, G.W. Wright, and R.B. James, Phys. Stat. Sol. 2, 1586 (2003).

4. A. Burger, K. Chattopadhyay, H. Chen, X. Ma, J.O. Ndap, M. Schieber, T.E. Schlesinger, H.W. Yao, J. Erickson, and R.B. James, Nucl. Instrum. Methods A 448, 586 (2000).

5. M.C. Duff, D.B. Hunter, A. Burger, M. Groza, J.P. Bradley, G. Giles, Z.R. Dai, D.R. Black, H. Burdette, and A. Lanzirotti, J. Mater. Res. 24, 1361 (2009).

6. P.Y. Tseng, C.B. Fu, M.C. Kuo, C.S. Yang, C.C. Huang, W.C. Chou, Y.T. Shih, H.Y. Hsin, S.M. Lan, and W.H. Lan, Mater. Chem. Phys. 78, 529 (2002).

7. Z. Medunic, M. Jaksic, Z. Pstuovic, and N. Skukan, Nucl. Instrum. Methods Phys. Res. 210, 237 (2003).

8. R. Gonzales, J.M. Perez, O. Vela, E. de Burgos, J.C. Oller, and V. Gostilo, IEEE Trans. Nucl. Sci. 52, 2076 (2005).

9. H. Hermon, M. Schieber, E.Y. Lee, J.L. McChesney, M. Goorsky, T. Lam, E. Meerson, H. Yao, J. Erickson, and R.B. James, Nucl. Instrum. Methods Phys. Res. A 458, 503 (2001).

10. C.M. Greaves, B.A. Brunett, J.M. Van Scyoc, T.E. Schlesinger, and R.B. James, Nucl. Instrum. Methods Phys. Res. A 458, 96 (2001).

11. M. Funaki, O. Tsutomu, S. Kazuyuki, and R. Ohno, Nucl. Instrum. Methods Phys. Res. A 436, 120 (1999).

12. R. Triboulet, T.N. Duy, and A. Durand, J. Vac. Sci. Technol. 3, 95 (1985)

13. C.L. Lingren, B. Apotovsky, J.F. Butler, F.P. Doty, S.J. Friesenhanh, A. Oganesyan, B. Pi, and S. Zhao, Mater. Res. Soc. Symp. Proc. 487, 263 (1998).

14. L. Teague, S. Hawkins, M.C. Duff, M. Groza, V. Buliga, and A. Burger, J. Electron. Mater. 38, 1522 (1999).

15. S. Hawkins, E. Villa-Aleman, M.C. Duff, D.B. Hunter, A Burger, M. Groza, V. Buliga, and D. Black, J. Electron. Mater. 37, 1438 (2008). 